\title{
Violência contra a mulher sob a ótica de pessoas usuárias da Atenção Básica
}

\author{
Violence against women from the perspective of Primary Care users \\ La violencia contra la mujer desde la perspectiva de los usuarios de la Atención Primaria
}

Recebido: 06/12/2021 | Revisado: 14/12/2021 | Aceito: 15/12/2021 | Publicado: 22/12/2021

Débora dos Santos Rodrigues
ORCID: https://orcid.org/0000-0001-7051-9682
Prefeitura Municipal de Rio Grande, Brasil
E-mail: debora-enfermagem @ hotmail.com
Camila Daiane Silva
ORCID: https://orcid.org/0000-0002-0739-4984
Universidade Federal do Rio Grande, Brasil
E-mail: camilad.silva@ yahoo.com.br
Daniele Ferreira Acosta
ORCID: https://orcid.org/0000-0001-5690-1076
Universidade Federal do Rio Grande, Brasil
E-mail: nieleacosta@ gmail.com
Victoria Leslyê Rocha Gutmann
ORCID: https://orcid.org/0000-0002-3457-7620
Universidade Federal do Rio Grande, Brasil
E-mail: victorialeslye@ gmail.com
Lisiane Ortiz Teixeira
ORCID: https://orcid.org/0000-0003-1402-8349
Universidade Federal do Rio Grande, Brasil
E-mail: lisiane.ortiz.teixeira@ gmail.com
Sibele da Rocha Martins
ORCID: https://orcid.org/0000-0001-7870-6642
Universidade Federal do Rio Grande, Brasil
E-mail: sibelemartins @ furg.br
Cristiane Lopes Amarijo
ORCID: https://orcid.org/0000-0002-4441-9466
Universidade Federal de Pelotas, Brasil
E-mail: cristianeamarijo@ @ahoo.com.br

\section{Resumo}

Esse estudo objetiva identificar a percepção de pessoas usuárias da atenção básica sobre a violência contra a mulher. Trata-se de uma pesquisa qualitativa, descritiva e exploratória, tendo como participantes 18 usuários dos serviços de saúde de nove unidades básicas de saúde da família do município de Rio Grande. A coleta de dados ocorreu entre outubro de 2019 e janeiro de 2020 por meio de uma entrevista gravada com questionário semiestruturado, além de solicitar aos participantes que elencassem palavras que lhes viessem naturalmente a mente ao ouvir o tema violência contra a mulher. Tais palavras foram analisadas pelo programa online e gratuito Wordcloud ${ }^{\circledR}$. O tratamento das entrevistas se deu pela Análise de Conteúdo. Obteve-se a aprovação no Comitê de Ética. Desta análise, emergiram três categorias: "Gênero e violência: reconhecimento das desigualdades"; "Sentimentos e a (in)compreensão frente a violência" e "Suporte à vítima de violência: serviços de proteção". Os participantes tiveram dificuldade de conceituar a palavra gênero, associando o termo diretamente à sexualidade das pessoas. Ainda, pontuaram reconhecer a existência da lei Maria da Penha, porém destacaram a fragilidade dos serviços de proteção apontados como ambientes preconceituosos e discriminatórios. É necessário incentivar a população para mudanças de hábitos e atitudes, tendo em vista que o comportamento violento segue um padrão pré-estabelecido vinculado a uma cultura machista e sexista. Palavras-chave: Violência; Violência contra a mulher; Atenção Primária à Saúde; Enfermagem.

\begin{abstract}
This study aims to identify the perception of people using primary care about violence against women. This is a qualitative, descriptive and exploratory study, with 18 health service users from nine basic family health units in the municipality of Rio Grande as participants. Data collection took place between October 2019 and January 2020 through a recorded interview with a semi-structured questionnaire, in addition to asking participants to list words that would naturally come to mind when hearing the theme of violence against women. These words were analyzed by the free online program Wordcloud®. The treatment of the interviews was done through Content Analysis. Approval was obtained from the Ethics Committee. From this analysis, three categories emerged: "Gender and violence: recognition of inequalities"; "Feelings and (in) understanding in the face of violence" and "Support for the victim of violence: protection services". The participants found it difficult to conceptualize the word gender, associating the term directly
\end{abstract}


to people's sexuality. Still, they pointed out to recognize the existence of the Maria da Penha law, however they highlighted the fragility of the protection services pointed out as prejudiced and discriminatory environments. It is necessary to encourage the population to change habits and attitudes, considering that violent behavior follows a preestablished pattern linked to a sexist and sexist culture.

Keywords: Violence; Violence against women; Primary Health Care; Nursing.

\section{Resumen}

El estudio tiene como objetivo identificar la percepción de las personas que utilizan la atención primaria sobre la violencia contra la mujer. Se trata de un estudio cualitativo, descriptivo y exploratorio, con 18 usuarios de servicios de salud de nueve unidades básicas de salud familiar del municipio de Rio Grande como participantes. La recolección de datos se realizó entre octubre de 2019 y enero de 2020 a través de una entrevista grabada con un cuestionario semiestructurado, además de pedir a los participantes que enumeren las palabras que naturalmente les vendrían a la mente al escuchar el tema de la violencia contra las mujeres. Estas palabras fueron analizadas por el programa online gratuito Wordcloud ${ }^{\circ}$. El tratamiento de las entrevistas se realizó mediante Análisis de Contenido. Se obtuvo la aprobación del Comité de Ética. De este análisis surgieron tres categorías: "Género y violencia: reconocimiento de las desigualdades"; "Sentimientos y (in) comprensión ante la violencia" y "Apoyo a la víctima de violencia: servicios de protección". Los participantes encontraron difícil conceptualizar la palabra género, asociando el término directamente a la sexualidad de las personas. Aún así, señalaron reconocer la existencia de la ley Maria da Penha, sin embargo destacaron la fragilidad de los servicios de protección señalados como entornos prejuiciados y discriminatorios. Es necesario incentivar a la población a cambiar hábitos y actitudes, considerando que el comportamiento violento sigue un patrón preestablecido ligado a una cultura sexista y sexista.

Palabras clave: Violencia; Violencia contra la mujer; Atención Primaria de Salud; Enfermería.

\section{Introdução}

A violência faz parte da existência humana desde a antiguidade, podendo ser verificada em diferentes contextos da vida. No que tange à violência contra mulher, existem diversas maneiras de praticar os atos sem utilizar a força física. Neste sentido, a Convenção de Belém do Pará, também conhecida como Convenção Interamericana para Prevenir, Punir e Erradicar a Violência Contra a Mulher, definiu a violência contra as mulheres como ações fundamentadas no gênero, que podem levar a morte, dano ou sofrimento, tanto físico, psicológico ou sexual, seja no espaço público ou privado (Oea, 1994).

No Brasil, a Lei no 11.340 de 2006, conhecida como Lei Maria da Penha, ganhou este nome em homenagem à Maria da Penha Maia Fernandes, vítima de violência doméstica que por longos vinte anos travou diversas batalhas jurídicas de modo a punir seu agressor. A referida lei foi alterada em 13 de maio de 2019, autorizando as medidas protetivas pela autoridade judicial ou policial (Brasil, 2019).

A violência contra as mulheres é um grande problema de saúde pública e de violação dos direitos humanos (Brasil, 2017). Estima-se que, no mundo, cerca de uma em cada três mulheres (35\%) sofreram violência física e/ou sexual por parte do parceiro, ou de terceiros durante a vida, sendo na maior parte dos casos, a violência infligida por parceiros. Quase um terço (30\%) das mulheres que estiveram em um relacionamento, relatam ter sofrido alguma forma de violência física e/ou sexual na vida por parte de seu parceiro (Brasil, 2017).

No Brasil houve um crescimento dos feminicídios no ano de 2017, com cerca de 13 assassinatos por dia, segundo os dados levantados pelo Atlas da Violência (Cerqueira et al., 2018). Ao todo, 4.936 mulheres foram mortas, o maior número registrado desde 2007. O Sistema de Informação sobre Mortalidade (SIM) registrou um crescimento expressivo de feminicídios no país, a cada 100 mil mulheres, 30,7\% foram mortas no período de 2007 a 2017.

$\mathrm{O}$ enfrentamento à violência contra a mulher é um trabalho árduo da comunidade em geral, homens e mulheres. Movimentos de organizações não governamentais, poder público, judiciário, legislativo e grupos de apoio trabalham incansavelmente para o fim da violência contra a mulher. O resultado dessas iniciativas se traduz no empoderamento das mulheres, que assumem a dianteira de sua própria defesa, sabendo o que devem fazer e a quem recorrer frente a um caso de violência. 
Nesse sentido, torna-se importante conhecer como pessoas da comunidade percebem a violência contra a mulher, pois ao evidenciar esse conhecimento do senso comum se pode avaliar as estratégias de enfrentamento empregadas, bem como aprimorar ações de prevenção na sociedade. Assim, este estudo teve como objetivo identificar a percepção de pessoas usuárias da atenção básica sobre a violência contra a mulher.

\section{Metodologia}

Trata-se de uma pesquisa exploratória, descritiva, com abordagem qualitativa. A abordagem qualitativa trabalha com o universo dos significados, motivos, aspirações, crenças, valores e atitudes, buscando a percepção do fenômeno dentro do seu contexto sociocultural (Minayo, 2001).

O estudo foi realizado no município de Rio Grande-RS que dispõe de uma cobertura de 25 unidades de saúde ligadas à Estratégia Saúde da Família, denominadas Unidades Básicas Saúde da Família (UBSF). Essas unidades são divididas em treze unidades urbanas, oito rurais e quatro litorâneas (Prefeitura, 2018). O estudo pretendia, inicialmente, incluir todas as unidades, no entanto, em decorrência do isolamento social pela COVID-19, as atividades nas unidades de saúde ficaram restritas aos serviços de saúde essenciais à comunidade, sendo canceladas as demais. Sendo assim, foi necessário interromper as coletas de dados deste estudo, com a inclusão de apenas nove Estratégias de Saúde da Família.

A coleta dos dados ocorreu no período de outubro de 2019 a março de 2020. Foram convidados dois usuários de cada unidade de saúde, um do sexo masculino e outro feminino, totalizando 18 usuários, nove mulheres e nove homens. O recrutamento dos participantes se deu através de abordagem aos usuários que estavam presentes na unidade de saúde, sem prejudicar seu atendimento no serviço. A coleta foi acordada com a responsável de cada unidade e realizada em local reservado de modo a respeitar o sigilo e a integridade de cada participante. Todos os participantes preencheram o termo de consentimento livre e esclarecido.

Primeiramente era solicitado aos participantes que elencassem palavras que viessem naturalmente à mente ao ouvir o termo "violência contra a mulher", a pesquisadora realizava o registro em um formulário de coleta próprio. Após era iniciada a gravação da entrevista, que não possuía limite de tempo e contava com um roteiro de perguntas abertas para a abordagem do tema. As palavras elencadas foram analisadas pela construção da nuvem de palavras, a qual foi elaborada a partir do software Wordcloud $^{\circledR}$, de acesso gratuito, público e online. Nele a palavra mais frequente é a que fica em destaque, ou seja, com tamanho maior do que as demais. A análise por nuvem de palavras é um método heurístico de análise, em que uma palavra é repetida várias vezes, usada para destacar com que frequência um termo ou categoria específica aparece em uma fonte de dados (Vasconcellos-Silva \& Araújo-Jorge, 2019). As entrevistas foram transcritas e tratadas pelo método proposto pela Laurence Bardin, que descreve a análise de conteúdo como um conjunto de técnicas de análise de comunicações que visa obter, por procedimentos sistemáticos e objetivos de transcrição do conteúdo a inferência de conhecimentos relativos às condições de produção/recepção destas mensagens (Bardin, 2011).

Este estudo faz parte de um macroprojeto de Pesquisa e Extensão, intitulado "Violência contra a mulher e o empoderamento de pessoas usuárias da atenção básica" aprovado pelo Núcleo Municipal de Educação em Saúde Coletiva (NUMESC) sob número 021/2019 e pelo Comitê de Ética sob parecer número 3.573.233 e C.A.A.E. número 18563719.2.0000.5324.

\section{Resultados e Discussão}

Participaram do estudo 18 usuários, sendo nove homens e nove mulheres com idade entre 18 e 60 anos e renda entre $\mathrm{R} \$ 89,00$ e $\mathrm{R} \$ 3.000,00$ mensais. A maioria desses participantes (78\%) relatou possuir companheiro, sendo que $22 \%$ dos entrevistados não possuíam filhos e $78 \%$ referiram ter entre um e quatro filhos. Em relação à orientação sexual, $100 \%$ dos 
participantes se declararam heterossexuais. Quanto ao nível de escolaridade, 39\% tinham ensino fundamental incompleto, 39\% médio incompleto, $17 \%$ superior incompleto e $5 \%$ médio completo. Com relação à cor da pele, $72 \%$ dos entrevistados se autodeclararam brancos, $11 \%$ pardos, $11 \%$ moreno e $6 \%$ da cor negra. Ao serem questionados sobre o tipo de religião que seguiam, $11 \%$ referiram acreditar em Deus, $28 \%$ relataram ser católicos, $11 \%$ evangélicos e $50 \%$ dos entrevistados não souberam informar ou não possuíam religião.

As palavras que foram elencadas pelos participantes formaram a nuvem de palavras (Figura 1). Nela, observa-se três palavras com maior relevância, ou seja, com maior frequência, "abuso", "negativo" e a expressão "sem motivo".

Figura 1. Nuvem de palavras da pesquisa intitulada "Violência contra a mulher sob a ótica de pessoas usuárias da atenção básica”. 2020.

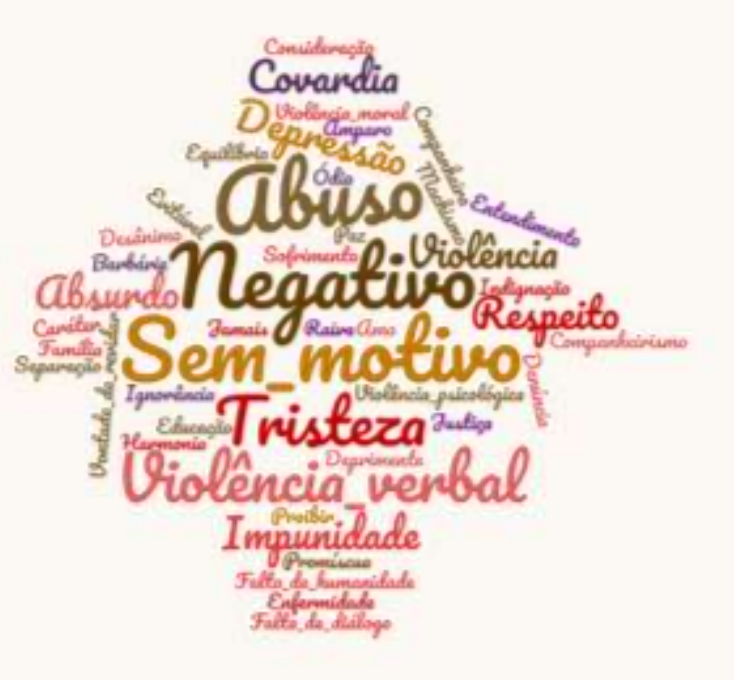

Fonte: Autores, por meio do uso do Wordcloud®.

Essas palavras estão intimamente ligadas às categorias analíticas que surgiram a partir da análise de conteúdo, sugerindo inconformidade e incompreensão frente à violência contra a mulher, reconhecendo que essa atitude causa revolta e indignação nas pessoas. Tal atitude não é tolerada, muito menos entendida, pela sociedade que se mostra contrária a determinadas condutas que violam os direitos humanos e ferem a dignidade das mulheres. O sentimento de impunidade segue presente entre os participantes, demonstrando a fragilidade do sistema e a necessidade de uma mudança de comportamento, tanto por parte da população quanto dos órgãos competentes. Dentre as formas de violência contra a mulher, os participantes enfatizaram a verbal e a moral. Cabe destacar que a Lei Maria da Penha define violência moral como qualquer conduta que configure calúnia, difamação ou injúria, e não apresenta definição para a violência verbal (Brasil, 2006). Na descrição de violência psicológica é possível perceber que o termo "verbal" elencado pelos participantes se encaixa, pois, inclui insultos, ridicularização, humilhação, manipulação e diminuição da autoestima. Essa nuvem de palavras ilustra as categorias que surgiram da análise de conteúdo que são apresentadas a seguir.

\section{Gênero e violência: reconhecimento das desigualdades}

A compreensão do termo gênero ainda é motivo de confusão entre a comunidade. Os participantes tiveram dificuldade em conceituá-lo ou associaram diretamente à orientação sexual de uma pessoa. 
Apesar disso, os participantes reconheceram as desigualdades impostas pela sociedade entre os sexos, feminino e masculino. Pontuaram existir diferenças de oportunidades nos âmbitos econômico, político, educacional e/ou cultural. Ainda, referiram a ocorrência de atos violentos contra as mulheres pelo simples fato de seu sexo ser repudiado.

"Não por muitos pensar, "ah, eu sou homem", não, para mim todos são iguais, acho que não deveria haver diferença tanto de trabalho, tratamento, salário, tudo." (P-07)

“Eu acho errado. Tipo, sem sentido nenhum brigar com uma mulher só por ela ser mulher.” (P-06)

A busca incessante pela igualdade entre os gêneros é uma luta original dos movimentos feministas. Com esses, algumas teorias e conceitos foram construídos como o de gênero que tem a finalidade de apontar as diferenças e hierarquias existentes entre homens e mulheres e desnaturalizar os próprios gêneros das pessoas (Colling, 2018). Grandes são os avanços sobre essa desnaturalização do conceito de gênero, que é popularmente entendido como sexo biológico do indivíduo. Desta forma o conceito de gênero, para o feminismo, não é uma ideologia e, sim, uma categoria analítica com a finalidade de identificar e denunciar as relações de desigualdade entre homens e mulheres na sociedade (Colling, 2018). Existe uma certa ideia pré-concebida de inferioridade da figura feminina em relação à masculina.

Ao analisar a inserção da mulher no mercado de trabalho formal, em que as relações de emprego são regidas pela consolidação das leis trabalhista (CLT), percebe-se que as mulheres concentram atividades socialmente identificadas como atribuição feminina, corroborando para a aplicação das distinções nos papéis de gênero. Esse tipo de atitude é uma barreira na trajetória profissional feminina. No Brasil, as dificuldades enfrentadas pelas mulheres são evidenciadas pela forma como os sexos se distribuem nas mais diversas ocupações laborais e setores econômicos. A inserção das mulheres no mercado de trabalho apresentou poucas alterações nas últimas décadas, apesar de a Constituição Federal de 1988 ter dado evidência à igualdade de gênero no trabalho (Cotrim et al., 2020).

O mercado de trabalho brasileiro é marcado pelas desigualdades salariais e principalmente pela segregação organizacional trabalhista. As funções predominantemente atribuídas às mulheres são vistas como uma extensão de suas características naturais e isto é usado como justificativa para salários inferiores ao dos homens. Esse fato faz com que muitas mulheres ainda continuem exercendo funções consideradas "femininas", adicionando assim um aumento da força de trabalho e diminuição de salários. Esta condição de constante injustiça traz como implicação uma segregação ocupacional por sexo no mercado de trabalho, institucionalizada por normas e práticas sociais contemporâneas (Teixeira, 2017).

Percebe-se que por mais que a divisão sexual do trabalho tenha se alterado nos últimos anos, a discriminação social permanece fomentando condições desiguais apesar das mulheres já exercerem cargo superior ao dos homens e profissões altamente qualificadas. Mesmo com todas as conquistas dos movimentos feministas, as mulheres ainda sofrem dificuldades para galgar postos de destaque e de maior responsabilidade no mercado de trabalho. Barreiras invisíveis são impostas diariamente e este fato pode estar ligado a dupla jornada de trabalho e a necessidade de conciliação entre vida profissional e vida familiar, tradicionalmente impostas as mulheres (Proni \& Proni, 2018).

Segundo dados do IBGE no ano de 2018, o rendimento médio das mulheres com idade entre 25 e 49 anos era R\$ 2.050, o que equivalia a 79,5\% do recebido pelos homens nesse mesmo grupo etário. Considerando as ocupações, a participação das mulheres era maior entre os trabalhadores dos serviços domésticos (95,0\%), professores do ensino fundamental (84,0\%), trabalhadores de limpeza de interior de edifícios, escritórios, hotéis e outros estabelecimentos (74,9\%) e dos trabalhadores de centrais de atendimento $(72,2 \%)$. Já no grupo de diretores e gerentes, as mulheres tinham participação de $41,8 \%$ e seu rendimento médio era de $\mathrm{R} \$ 4.435$ correspondendo a 71,3\% do recebido pelos homens ( $\mathrm{R} \$ 6.216)$. As funções com maior nível de instrução também mostram rendimentos discrepantes. Tanto professores do ensino fundamental quanto 
professores universitários recebem diferentes salários para profissionais do sexo masculino e feminino, sendo os homens os detentores das maiores rendas. Outras ocupações de nível de instrução mais elevado, como Médicos especialistas e Advogados, mostravam participações femininas em torno de $52 \%$ e uma diferença maior entre os rendimentos de mulheres e homens, com percentuais de 71,8\% e 72,6\%, respectivamente (Ibge, 2019).

Fontes da Pesquisa Nacional por Amostra de Domicílios Contínua (PNAD) apontaram que o número de mulheres no Brasil é superior ao de homens. A população brasileira é composta por 51,8\% de mulheres e 48,2\% de homens (Ibge, 2019). Ainda assim, no que se refere ao papel da mulher na política, nas eleições de 2017 a bancada feminina eleita para o legislativo federal alcançou a marca de 77 cadeiras ocupadas por mulheres representando apenas 13\% das 513 vagas disponíveis (Ibge, 2019). Este campo político sempre foi visto pela sociedade como um local exclusivamente masculino, o que sob a ótica da democracia e da inclusão política, necessita de mecanismos que acabem com essa estruturação retrógrada, dando acesso a diferentes grupos sociais, não só às mulheres, mas também grupos minoritários na tomada de decisões. Este meio de acesso pode ser concretizado por ações afirmativas, que garantam que grupos excluídos tenham acesso à esfera social, política e econômica (Sabino \& Lima, 2015).

Frente ao exposto, é possível perceber que a violência contra a mulher é permeada pelas questões de gênero e que a sociedade precisa reconhecer este fato, para sepoder modificar a forma de agir, pensar e reproduzir essas desigualdades. Apesar dos avanços, as mulheres ainda possuem muito a conquistar, especialmente no que tange ao fim da violência contra este grupo. Parte dessa violência está baseada nas construções histórias e sociais sobre as questões de gênero e as relações de poder presentes nos papéis de gênero impostos a mulher (Santos et al., 2019). É comum a busca por motivos reais que levaram o agressor a agir com violência, tentando disfarçar o impulso do ato em si, de modo que se busca uma justificativa persuasiva que motive a agressão, subentendendo que o homem sempre tem a razão na discussão (Santos et al., 2019).

\section{Sentimentos e a (in)compreensão frente a violência}

A ocorrência da violência foi compreendida pelos participantes como uma manutenção da postura masculina, justificada pelo machismo. Os participantes citaram a diferença entre os sexos, expondo a mulher, ainda, como uma propriedade do homem. Alguns participantes reconheceram a existência dos diferentes tipos de violência que acometem as mulheres.

\footnotetext{
"A violência em si não é só a fisica, pode ser tanto um xingamento, ofender tua moral ou te coagir dentro da tua casa, eu acredito que seja isso." (P-14)
}

"Nada do que temos aqui é nosso, tudo é emprestado. Agora, imagine um ser humano. Acontece que as pessoas querem ser proprietárias daquela pessoa" (P-01)

Os participantes reconheceram que a violência é considerada algo normal por ser perpetuada de geração em geração, necessitando que essa cultura seja rompida por meio da educação das crianças.

"É que acaba que achamos normal, [...] desde criança a gente vai achando que "ah, é normal, brigaram, ele deu um tapa nela, ela se defendeu, deu nele também, bateu [...]”. Só que depois vai analisar e hoje, eu como mãe, vendo meu filho, o que eu ensino para ele, [que] não tem que bater em ninguém, por nada sabe, muito menos numa mulher. Na escola tem, briguinha, entre criança e tal. Eu acho que é mais questão de educação assim sabe” (P-11) 
Essa perpetuação pode estar justificada pela ocorrência prévia da violência no lar, no ambiente privado dos participantes, seja como vítimas, como pessoas que assistiram uma situação de violência ou que ficaram sabendo sobre o ato.

"Isso que eu falei. Eu sinto raiva. Eu não gosto. Eu já vi a minha mãe, um companheiro dela bateu nela e eu me meti e não gostei o que ele fez nela, deixou ela toda roxa. E esse companheiro meu, não esse, o outro, deixou meu braço todo roxo e minhas pernas toda roxa porque me bateu, aí não gostei também, o jeito que ele fez. Aí eu achei errado o que ele fez comigo." (P-08)

“...é muita covardia, acho que, tudo assim, eu tenho nojo sabe. Tem horas que eu olho pro meu pai e dá um nojo dele, eu fico pensando "mas homem abusado" e ainda dá desculpa "ah, estava bêbado"[...] é que minha mãe não tinha coragem sabe, caso contrário eu tinha matado ele, tinha matado, porque onde já se viu, sabe” (P-11)

Apesar dos participantes pontuarem a questão de gênero, cultural e social para a ocorrência da violência, eles ainda possuem dificuldade em compreender o motivo de ocorrer e da mulher permanecer no relacionamento violento.

"A gente não consegue entender o que se passa na cabeça de uma mulher quando ela está nessa situação porquê ela não está contente, mas ao mesmo tempo ela não consegue se desvencilhar, é algo muito psicológico para se conseguir entender o que está acontecendo e também para ela consiga sair desse meio. E o homem eu também não sei o que acontece, não consigo achar que seja apenas doença porque acredito que tem muita maldade no meio, acho que não dá para tratar apenas como doença." (P-17)

O homem ainda tem a crença de que a mulher é um objeto de propriedade particular. Este fato ainda é perpetuado pelas famílias, resultado de um patriarcado historicamente comum entre a sociedade. Patriarcado é um sistema presente na sociedade em que os homens são detentores do poder e assim predominam em funções de liderança tanto nos âmbitos políticos, morais, no controle da sociedade. No cenário familiar, o pai detém a autoridade sobre as mulheres e as crianças (Azevedo, 2018). Semanticamente falando, patriarcado é uma palavra de origem grega advinda da combinação entre duas palavras, pater que significa pai e arkhe que significa origem e comando. Desta forma, pode-se definir patriarcado como autoridade do pai (Delphy, 2009).

A maternidade, o papel de esposa e submissa ao homem reforçam a ideia de que ser do sexo feminino é sinônimo de inferioridade ao sexo masculino e que à mulher caberia menos direitos. Essa suposta inferioridade faz com que a mulher seja subtraída de seus direitos e de sua liberdade de escolha sobre diversos traços da sua vida, principalmente sobre seu corpo e suas opiniões, fazendo com que ela seja um elemento neutro na sociedade machista (Santos et al., 2019). A violência de gênero pode atingir o indivíduo isoladamente como também coletivamente. Ela acontece de diferentes formas e se concretiza quando os valores humanos não são considerados. A violência de gênero ocorre no vínculo afetivo que pode envolver dois homens ou duas mulheres (Benincá, 2016).

As raízes da violência são muito profundas e buscam uma reflexão acerca dos motivos pelos quais famílias inteiras vivem em ambientes violentos e o porquê a mulher aceita conviver com a violência dentro do seu lar. Um estudo identificou circunstâncias mantenedoras para a permanência em um relacionamento abusivo, sendo elas: a esperança sobre a mudança de comportamento do parceiro, a dependência financeira e emocional, a preocupação com a criação dos filhos, a falta da rede de apoio e o comportamento passivo por parte da vítima (Pereira; Camargo \& Aoyama, 2018). 
A violência doméstica contra mulheres é um fenômeno social que é inerente ao comportamento humano e permanece ativo dentro de muitos lares na sociedade contemporânea se mantendo presente por um padrão histórico-cultural. Segundo estudo realizado por Silva, Gomes, Oliveira, Amarijo, Acosta \& Mota. (2016) com base na teoria da representação social, o sentimento de medo é um sentimento comum tanto de vítimas de violência quanto de profissionais, sendo esse um fator extremamente relevante na realização da denúncia. Já para Góes (2019) a vergonha social é um fator determinante para que mulheres convivam com a violência e não consigam se desvencilhar deste ciclo. O medo e a vergonha fazem parte de uma gama de sentimentos na vida dessas mulheres, sendo eles fundamentais para a sujeição das vítimas a seus agressores e a permanência nos relacionamentos abusivos e violentos.

A perpetuação da violência como algo normal foi explicada pelos participantes deste estudo pela ocorrência prévia de violência nos lares, durante a infância. Dessa forma, a educação de crianças e jovens no enfrentamento a violência é de extrema importância. Para mudar a cultura da violência no contexto familiar e escolar é necessário incluir a abordagem da Educação em Gênero para Crianças como meio de Prevenção da Violência de Gênero no Cotidiano Escolar. É fundamental que se crie espaços de discussão, com os pais com a finalidade de coibir e erradicar as diversas formas de violência (Alkimim \& Janini, 2019).

\section{Violência contra a mulher e os serviços de proteção}

Frente a ocorrência da violência, os participantes referiram ser preciso dar o suporte às vítimas. Umas das formas é não julgar a mulher que acabou de ser agredida, pois, estaria causando mais uma violência contra ela. Outra forma, é a busca por um serviço especializado, ou seja, a Delegacia da Mulher.

“...eles riem, eles debocham, porque é fato, eu já acompanhei [...]"Ah, é a segunda ou terceira vez que tu apanhas, não cansou ainda? ou então, Ah, pega tuas coisas e vai embora de casa, preferes vais apanhar?" Acredito que esse não é o momento certo e não seria o correto de se dizer para uma pessoa que acabou de ser agredida pelo marido, pelo pai, por quem for, entendeu? Por que "ah, você não cansou de apanhar?” (P-12)

Os participantes ainda afirmaram que os mesmos locais tidos como referência para busca de ajuda, são também vistos como ambiente discriminadores, preconceituosos e inseguros para as vítimas, com profissionais que demonstram desrespeito, de ética e de empatia.

"Acho até que as vezes as medidas protetivas, como chamam, são muito... fica frágil ainda" (P-07)

“...nós a levamos para Delegacia, e a única coisa que eles fizeram foi uma medida daquelas que tem que ficar sei lá quantos metros longe, o cara veio de novo e a matou depois. Então, eu acho que é praticamente nula porque eles não fazem nada pra ajudar. Eles debocham, ainda tinha um cara que estava debochando, tipo, citando o Bolsonaro, entre outras coisas da situação, a mulher ali, toda machucada, passando por várias coisas e ainda tu vê um policial debochando na tua frente como se fosse nada. Então é, deprimente...” (P-17)

Apesar de conhecerem serviços de apoio à vítima e relatarem o suporte online e telefônico, os participantes referiram que as vítimas demoram a buscar por ele, algumas movidas pelo medo.

"Serviço eu conheço, o problema é que elas demoram muito para procurar. Quando procuram, já é tarde." (P-10) 
"Acho assim, eu não sei, não viveria com um homem que faz isso com as mulheres... eu denunciaria, logicamente, mas muitas vezes elas não fazem essas denúncias por medo" (P-05)

No entanto, ainda que acreditem que a lei ampara a mulher nestas situações de violência pelo parceiro, os participantes apontam fragilidades e lacunas que os levam a sentirem falta de medidas mais duras para os agressores. Com a promulgação da Lei 11.340/06, a tão conhecida Lei Maria da Penha, inicia-se no país um momento diferente de luta e enfrentamento da violência doméstica contra a mulher. O papel desempenhado pela mulher na sociedade vem mudando desde a implantação da lei, e assim novos espaços são conquistados com avanços significativos referentes a consolidação dos Direitos das Mulheres Brasileiras, consagrados pela promulgação da Constituição Federal de 1988 que trata da plena igualdade de direitos e obrigações entre homens e mulheres (Balz, 2015).

Segundo Dias (2017) o grande mérito da lei Maria da Penha é garantir a concessão de medidas protetivas de urgência. Embora não haja criação de novos tipos penais, os delitos anteriormente reconhecidos como domésticos, deixam de ser considerados banais, fazendo-se possível decretar a prisão em flagrante e proibindo a permissão de benefícios. Ainda que a implantação da Lei e das medidas protetivas sejam ferramentas de extrema importância para o enfrentamento da violência contra a mulher, elas isoladas não conseguem aplacar o grande número de casos de violência no país. O Brasil ainda se encontra no quinto lugar na classificação de países que mais matam mulheres no muno. Acredita-se que esforços devem ser somados para o fim da existência deste comportamento agressivo por parte da sociedade com implantação de punições mais justas e severas (Conceição et al., 2020).

As Delegacias Especializadas no Atendimento à Mulher (DEAMs) são unidades especializadas da Polícia Civil e estão distribuídas em todo território nacional. As DEAMS são responsáveis pelas ações de prevenção, proteção e investigação dos crimes de violência doméstica e violência sexual contra as mulheres. Elas também desenvolvem ações voltadas a esse atendimento, tais como registro de boletim de ocorrência, solicitação das medidas protetivas de urgência nos casos de violência doméstica e familiar contra as mulheres e realização de investigação dos crimes (Brasil, 2010).

Para desenvolver estratégias de prevenção, o Governo Federal instituiu a obrigatoriedade da notificação compulsória em casos de violência contra a mulher por meio da Lei $n^{\circ}$ 10778, de 24 de novembro de 2003 diminuindo as subnotificações destes casos. Sendo assim, todo caso de violência contra a mulher, seja ela física, sexual ou psicológica atendido nos serviços públicos ou privados deve ser notificado (Brasil, 2003).

Além de toda dor e sofrimento infligidos à mulher, muitas vezes ela ainda é surpreendida com atitudes machistas e preconceituosas no ambiente em que deveria se sentir segura. Os serviços de saúde, as Delegacias Especializadas no Atendimento à Mulher (DEAM) ou o Instituto Médico Legal (IML) estão entre os primeiros locais de acolhimento destas vítimas. Esses serviços, por vezes, é marcado pela falta de privacidade, exposição, atitudes discriminatórias e juízos de valor, com funcionários expondo mulheres a constrangimentos e comentários depreciativos levando a vítima a se sentir responsabilizada e culpada por estar vivenciando um relacionamento abusivo/violento (Moreira, 2020). As atitudes discriminatórias e moralistas com relação ao comportamento e a vida pessoal das mulheres corroboram para a postura sexista e preconceituosa impregnada nas relações sociais, reforçando as diferenças entre os gêneros. Esse fato fortalece a vulnerabilidade feminina, perpetuando o círculo vicioso entre a violência interpessoal e a institucional, impedindo a interrupção da cadeia de violência (Moreira, 2020).

Nesse contexto surge o termo violência institucional definida como aquela praticada, por ação ou omissão, nas instituições públicas ou privadas prestadoras de serviços. Essa forma de violência é praticada por agentes que deveriam prestar uma atenção humanizada, preventiva e reparadora de danos (Chai; Santos \& Chaves, 2018). Muitas mulheres se sentem 
amedrontadas e vulneráveis frente a situação de violência a qual foi exposta e tudo que ela necessita no momento da denúncia é de um ambiente acolhedor com profissionais que não as desqualifiquem como ser humano.

Frente a isso, acredita-se que seja necessário não apenas tratar os casos de violência com punições mais severas, mas sim, elaborar ações preventivas e educativas que incentivem boas práticas e diálogos abertos sobre a igualdade de gênero, sobre o respeito e a intolerância. Desta forma, se faz necessário envolver não só mulheres nas ações de enfrentamento à violência, incluindo também jovens e crianças nestas ações, assim como os homens (Acosta; Gomes; Fonseca \& Gomes, 2015).

\section{Considerações Finais}

A violência contra mulher é um acontecimento histórico firmado na antiguidade e que se perpetua em pleno século XXI. Parte deste fato é justificado pelo patriarcado e a ideia de uma suposta inferioridade feminina, além da crença de que cabe a mulher acatar e aceitar o domínio masculino nas relações. Frente a isso, torna-se imperativo a elaboração de práticas que auxiliem na mudança de comportamento da sociedade e as atividades de educação são essenciais para a mudança desses comportamentos agressivos. Além disso, percebe-se que existe uma falta de compreensão sobre o significado do termo gênero, vinculando a palavra à sexualidade dos indivíduos, fato que fortalece a desigualdades entre os sexos, e consequentemente uma perpetuação de atitudes violentas.

Durante o estudo os participantes relataram a fragilidade que visualizam ter os serviços de proteção à vítima. Embora as DEAMs sejam percebidas como locais de proteção e denúncia, também são tomadas como ambientes preconceituosos e julgadores. Outro fato que manifesta precariedades do sistema, elencado pelos participantes, são as falhas nos cumprimentos das medidas protetivas. Embora garantidas por lei, os participantes percebem uma falta de uma fiscalização mais efetivas de modo a coibir certas atitudes violentas e a morte das vítimas.

\section{Referências}

Acosta, D. F., Gomes, V. L. O., Fonseca, A. D., Gomes, G. C. (2015). Violence against women commited by intimate partners: (in)visibility of the problem. Texto \& Contexto - Enfermagem, 24(1), 121-127. http://dx.doi.org/10.1590/0104-07072015001770013.

Alkimim, M. A. \& Janini, T. C. (2019). O combate ao cyberbullyng como forma de concretização do direito fundamental à educação das crianças e dos adolescentes. Revista Jurídica Cesumar, 3(19), 753-775. http://www.mpsp.mp.br/portal/page/portal/documentacao_e_divulgaca o/doc_biblioteca/bibli_servicos_produtos/bibli_boletim/bibli_bol_2006/Rev-JurCESUMAR_v.19_n.3.pdf\#page=106.

Azevedo, F. M. C. (2018). 0 conceito de patriarcado nas análises teóricas das ciências sociais: uma contribuição feminista. Revista Três Pontos: Dossiê Múltiplos Olhares sobre Gênero, 13(1), 13-20. <https://periodicos.ufmg.br/index.php/revistatrespontos/article/view/3386>.

Balz, D. F. (2015). A lei Maria da Penha e a in: eficácia das medidas protetivas. Trabalho de Conclusão do Curso de Graduação em Direito objetivando a aprovação no componente curricular Trabalho de Curso - TC. Universidade Regional do Noroeste do Estado do Rio Grande do Sul.

Bardin, L. (2011). Análise de conteúdo. Edições 70.

Benincá, L. M. M. (2016). A educação em gênero para crianças na prevenção da violência de gênero no cotidiano escolar. Curso de Curso de Especialização Ead Gênero e Diversidade na Escola, Centro de Filosofia e Ciências Humanas Instituto de Estudos de Gênero, Universidade Federal de Santa Catarina. https://repositorio.ufsc.br/bitstream/handle/123456789/173893/TCC\%20GDE\%20LEONIRCE\%20\%2024-2-17\%20-\%20PDF.pdf?sequence=1\&isAllowed=y.

Brasil. (2003). Lei 10.778, de 24 de novembro de 2003. Estabelece a notificação compulsória, no território nacional, de caso de violência contra a mulher que for atendida em serviços de saúde públicos ou privados. http://www.planalto.gov.br/ccivil_03/leis/2003/110.778.htm.

Brasil. (2006). Lei $n^{\circ} 11.340$, de 7 de agosto de 2006. Dispõe sobre os mecanismos para coibir a violência doméstica e familiar contra a mulher e dá outras providências. Diário Oficial da República Federativa do Brasil. Brasília, DF, 7 ago. 2006. http://www.planalto.gov.br/ccivil_03/_Ato20042006/2006/Lei/L11340.htm

Brasil. (2010). Norma Técnica de Padronização das Delegacias Especializadas de Atendimento às Mulheres. Secretaria de Políticas para as Mulheres. Brasília, 2010. http://www.spm.gov.br/lei-maria-da-penha/lei-mariada-penha/norma-tecnica-de-padronizacao-das-deams-.pdf

Brasil. (2017). Portaria $n^{\circ}$ 2.436, de 21 de setembro de 2017. Dispõe sobre a Política Nacional de Atenção Básica, estabelecendo a revisão de diretrizes para a organização da Atenção Básica, no âmbito do Sistema Único de Saúde. Diário Oficial da República Federativa do Brasil. Brasília. <http://bvsms.saude.gov.br/bvs/saudelegis/gm/2017/prt2436_22_09_2017.html>. 
Brasil. (2019). Lei 13.827 de 13 de maio de 2019 altera Lei Maria da Penha. Diário Oficial da República Federativa do Brasil. Brasília, DF, Brasília. http://www.planalto.gov.br/ccivil_03/_ato2019-2022/2019/lei/L13827.htm

Cerqueira, D. et al. (2018). Atlas da Violência 2018. Rio de Janeiro: Instituto de Pesquisa Econômica Aplicada (IPEA). http://www.ipea.gov.br/portal/images/stories/PDFs/relatorio_institucional/180604_atlas_da_violencia_2018.pdf

Colling, L. (2018). Gênero e sexualidade na atualidade. Salvador: UFBA, Instituto de Humanidades, Artes e Ciências, Superintendência de Educação a Distância. https://educapes.capes.gov.br/bitstream/capes/430946/2/eBook_\%20Genero_e_Sexualidade_na_Atualidade_UFBA.pdf

Chai, C. G., Santos, J. P. \& Chaves, D. G. (2018). Violência institucional contra a mulher: o Poder Judiciário, de pretenso protetor a efetivo agressor. Revista Eletrônica do Curso de Direito da UFSM, 13(2), 640-665. https://periodicos.ufsm.br/revistadireito/article/view/29538

Conceição, M. V., Assunção, E. K. R. \& Gonçalves, J. R. (2020). Violência contra a mulher e a ineficácia de medidas protetivas. Revista Processus de Estudos de Gestão, Jurídicos e Financeiros, 11(40), 158-167. <http://periodicos.processus.com.br/index.php/egjf/article/view/211https:// doi.org/10.6084/m9.figshare.12567896.

Cotrim, L. R. et al. (2020). Desigualdade de gênero no mercado de trabalho formal no Brasil. Texto Para Discussão: Unicamp, 383(s/n), 01-29. https://www.eco.unicamp.br/images/arquivos/artigos/TD/TD383.pdf.

Delphy, C. (2009). Patriarcado (teorias do). In: Hirata, H. et al. (org.). Dicionário Crítico do Feminismo. Editora UNESP: 173-178.

Dias, M. B. Medidas protetivas mais protetoras. http://www.mariaberenice.com.br/manager/arq/(cod2_13014)Medidas_protetivas_mais_protetoras.pdf.

Góes, E. D. A. (2019). A vergonha social e o medo: obstáculos para a superação da violência doméstica contra a mulher. Brazilian Journal Of Development, 5(11), 23627-23645. http://dx.doi.org/10.34117/bjdv5n11-069.

Ibge. (2019). Síntese de indicadores sociais: uma análise das condições de vida da população brasileira - 2019. IBGE.

Minayo, M. C. S. (2013). Violência e Educação: impactos e tendências. Revista Pedagógica, 15(31), 249-264. <https://bell.unochapeco.edu.br/revistas/index.php/pedagogica/article/view/2338/1413〉.

Moreira, G. A. R., Vieira, L. J. E. S., Cavalcanti, L. F., Silva, R. M., Feitosa, A. R. (2020). Manifestações de violência institucional no contexto da atenção em saúde às mulheres em situação de violência sexual. Relações de Gênero, Mulheres e Feminismos. Saúde e Sociedade, 29(1), 1-15. https://doi.org/10.1590/S0104-12902020180895.

Oea. (1994). Organização dos Estados Americanos. Convenção interamericana para prevenir, punir e erradicar a violência contra a mulher, "convenção de belém do pará". http://www.cidh.org/basicos/portugues/m.belem.do.para.htm

Pereira, D. C. de S., Camargo, V. S., \& Aoyama, P. C. N. (2018). Análise funcional da permanência das mulheres nos relacionamentos abusivos: Um estudo prático. Revista Brasileira De Terapia Comportamental E Cognitiva, 20(2), 10-25. https://doi.org/10.31505/rbtcc.v20i2.1026

Prefeitura municipal do rio grande. (2018). Secretaria de Município da Saúde. Relatório de gestão segundo quadrimestre/2018: relatório de desempenho. Rio Grande.

Proni, T. T. R. W. \& Proni, M. W. (2018). Discriminação de gênero em grandes empresas no Brasil. Rev. Estud. Fem., 26(1), e41780. https://doi.org/10.1590/1806-9584.2018v26n141780.

Sabino, M. J. C. \& Lima, P. V. P. S. (2015). Igualdade de gênero no exercício do poder. Rev. Estud. Fem. $23(3), \quad 713-734$. http://www.scielo.br/scielo.php?pid=S0104-026X2015000300713\&script=sci_abstract\&tlng=pt.

Santos, R. G. et al. (2019). Violência contra a Mulher à Partir das Teorias de Gênero. Id on Line Rev.Mult. Psic., 13(44), 97-117.

Silva, C. D., Gomes, V. L. O., Oliveira, D. C., Amarijo, C. L., Acosta, D. F. \& Mota, M. S. (2016). Representação da violência doméstica contra mulheres entre profissionais de saúde: idade como atributo de diferenciação. Revista Enfermagem Uerj, 24(3), 1-6. http://dx.doi.org/10.12957/reuerj.2016.13212.

Teixeira, M. O. (2017). Um olhar da economia feminista para as mulheres: os avanços e as permanências das mulheres no mundo do trabalho entre 2004 e 2013. Tese (Doutorado)- Universidade Estadual de Campinas, Instituto de Economia, Campinas.

Vasconcellos-Silva, P. \& Araújo-Jorge, T. (2019). Análise de conteúdo por meio de nuvem de palavras de postagens em comunidades virtuais: novas perspectivas e resultados preliminares. Atas - Investigação Qualitativa em Saúde/Investigación Cualitativa en Salud, 2(esp.). https://proceedings.ciaiq.org/index.php/CIAIQ2019/article/view/2002 